\title{
Escrever para não esquecer: entrevista com Scholastique Mukasonga
}

\author{
Larissa Esperança da Silva ${ }^{1}$ \\ Lucília Souza Lima Teixeira ${ }^{2}$ \\ Mariana Cunha Firmino ${ }^{3}$ \\ Sandra Coeli Barbosa dos Santos ${ }^{4}$ \\ do coletivo de leitura literária Les Leillas
}

São Paulo, SP - 15/11/2019

SCHOLASTIQUE MUKASONGA, NASCIDA EM 1956 EM RUANDA, É UMA ESCRITORA FRANCÓFONA sobrevivente do genocídio dos tutsis ocorrido nos anos 1990. Ela emigrou para a França nesse período e ali estabeleceu residência trabalhando como assistente social. Escrever passou a ser uma necessidade para salvar a memória ${ }^{5}$ :

Onde estão eles hoje? Na cripta memorial da igreja de Nyamata, crânios anônimos entre tantas ossadas? $\mathrm{Na}$ brousse, sob os espinheiros, em uma fossa que ainda não veio a público? Copio inúmeras vezes o nome que ainda não veio a público? Copio inúmeras vezes o nome deles no caderno de capa azul, quero provar a mim mesma que eles existiram, pronuncio seus nomes um a um na noite silenciosa. Sobre cada nome devo definir um rosto, pendurar um retalho como lembrança. Não quero chorar, sinto as lágrimas escorrerem pelas minhas faces. Fecho os olhos, esta será mais uma noite sem sono. Tenho muitos mortos a velar. ${ }^{6}$

Depois de conferências realizadas em São Paulo em novembro de 2019 sobre três de suas obras traduzidas para o português e publicadas pela editora Nós: A mulher dos pés descalços (2017), Nossa Senhora do Nilo (2017) e Baratas (2018), a autora Scholastique Mukasonga, acompanhada de seu filho Aurélien, gentilmente, nos concedeu uma entrevista em seu hotel, que foi gravada em áudio antes de seu embarque para Nova York, onde concorreu ao prêmio National Book Awards 2019 por A mulher dos pés descalços. Segundo a escritora, esse é o seu livro mais conhecido nos Estados Unidos e no Brasil, lançado na FLIP em Paraty em 2017. Depois de transcrever integralmente a gravação de uma hora de entrevista e traduzi-la, procuramos cortar repetições e hesitações

\footnotetext{
${ }^{1}$ Mestranda em Culturas e Literaturas Europeias pelo programa Erasmus Mundus na Université de Strasbourg e Università di Bologna (1arissa.aesilva@gmail.com).

${ }^{2}$ Doutora em Letras pelo programa de pós-graduação Estudos Linguísticos, Literários e Tradutológicos em francês da Faculdade de Filosofia, Letras e Ciências Humanas da Universidade de São Paulo (FFLCH-USP) / (luciliatex@gmail.com)

${ }^{3}$ Graduanda em Letras Português-Francês pela Faculdade de Filosofia, Letras e Ciências Humanas da Universidade de São Paulo (FFLCH-USP) / (mariana.firmino@usp.br)

${ }^{4}$ Doutoranda pelo Programa Letras e Tradução do Departamento de Letras Modernas da Faculdade de Filosofia, Letras e Ciências Humanas da Universidade de São Paulo (FFLCH-USP) / (sandracoeli@gmail.com)

${ }^{5}$ As citações presentes nessa entrevista foram escolhidas pelas entrevistadoras.

${ }^{6}$ MuKasonga, S. Baratas. Tradução Elisa Nazarian. São Paulo: 2018, p. 18.
} 
características da oralidade afim de tornar a leitura mais fluida. A escritora teve ciência de todo o processo até a publicação desta entrevista.

Mukasonga começa sua fala destacando que, na maioria dos países, suas editoras são mulheres:

Scholastique Mukasonga (SM): Seguimos o ritmo de Simone Paulino, minha editora no Brasil. Em todo lugar, são editoras mulheres: Argentina, Itália, Espanha, Dinamarca, só tem um homem editor, na Alemanha. A Nós é jovem, cinco anos não é nada para uma editora. Acho que ela é muito ágil, será tão importante como a Gallimard, talvez não igual, mas não muito longe disso. Este ano, a editora de Nova York traduziu $A$ mulher de pés descalços (The Barefoot Woman, 2018). Com esse livro, sou finalista de um prêmio importante em Nova York, que se chama National Book Award ${ }^{7}$. Estamos torcendo!

Les Leïlas (LL): Somos um coletivo de leitura literária composto por mulheres, Les Leïlas, nome de mulheres que nos inspiram, como Leila Diniz, Leïla Slimani, Leïla Sebbar, Leila Khaled, Leyla Perrone-Moisés. Nos juntamos para participar do primeiro Choix Goncourt do Brasil e ler a seleção da Academia Goncourt dos finalistas de 2018, quando escolhemos Frère d'Âme de David Diop. Continuamos a nos encontrar, ler, discutir, procurar novos livros, e sobretudo, divulgar a literatura francófona contemporânea no Brasil, visto que na faculdade temos acesso a autores clássicos como Victor Hugo, Balzac, Flaubert, dentre outros.

SM: Formidável! É maravilhoso que vocês tenham acesso a essa literatura!

LL: Sim, mas e os contemporâneos? É preciso achar soluções, alternativas para trazê-los.

SM: Vocês devem ter um forte apoio do Institut Français, então?

LL: Acabamos de começar, nosso projeto não tem ainda um ano.

Ao mencionar o Institut Français, organização pública francesa que tem como objetivo promover a cultura francesa no exterior, a autora comenta sobre a importância da divulgação da língua francesa frente a hegemonia do inglês e do papel político que ela exerce no contexto dos países francófonos na África.

SM: Desde janeiro de 2019, a OIF, Organização Internacional da Francofonia, foi confiada à uma ruandesa que tem o título de Secretária Geral da Francofonia. Uma mulher. Uma mulher forte. Cuidado com as ruandesas! [risos] Tenho muito orgulho disso. Em um determinado momento, Ruanda se tornou anglófona por diversas razões, mas historicamente é francófona. Acho que já disse que não sou de uma colônia francesa, mas belga. No nosso país, foram os belgas que escolheram nos ensinar o francês e não a língua valona ou o neerlandês. Louise Mushikiwabo, que está à frente da OIF hoje, é a mulher forte de Ruanda, uma das personalidades mais influentes na política do país. Ela ocupou o cargo de ministra das Relações Internacionais desde o fim do genocídio. É realmente o braço direito do presidente. Em janeiro de 2019, ela deixou o ministério para assumir a OIF, por uma simples razão: em Ruanda nós temos necessidade absoluta de ocupar todo espaço que se apresenta. Não

${ }^{7}$ O National Book Award é um dos mais importantes prêmios literários dos Estados Unidos da América. O prêmio é entregue desde 1950 em ao menos uma categoria. Atualmente, existem quatro categorias: ficção, não-ficção, poesia e literatura juvenil. $\mathrm{O}$ prêmio é administrado pela Fundação National Book. Disponível em: <https://www.nationalbook.org/>. Acesso em: 28 ago 2020. 
negligenciamos nada. Ruanda é bem pequeno. Simone me disse que São Paulo tem 14 milhões de habitantes! Ruanda inteiro, são 12 milhões! Se desembarcássemos todos em São Paulo vocês não saberiam que chegamos, mas veriam muito colorido de uma só vez. [risos]

Nós temos uma influência importante porque não é uma questão de quantidade, mas de qualidade. Chegamos tão no fundo do poço que hoje não deixamos passar nada. Colocamos no centro a palavra dignidade, que faz com que todo mundo se mobilize para dar uma imagem, não apagar a história, mas passar uma imagem dos ruandeses que são capazes de cuidar de si mesmos.

Então, o fato de, em 2011, Ruanda ter aceitado o desafio de se tornar anglófona preocupou muito a França, porque somos vizinhos da República Democrática do Congo. Em Kinshasa, havia um ditador chamado Mobutu que era francófono e que realmente apoiava a maior parte da francofonia. Desta forma, Ruanda, enquanto anglófona, poderia ter uma influência sobre o Congo porque, naquele momento, se o país fosse anglófono, nos ligaríamos novamente aos grandes países vizinhos, Tanzânia, Uganda, Quênia, que são anglófonos, e se influenciássemos o Congo, tudo iria por água abaixo, a francofonia cairia.

O presidente francês Macron foi o primeiro a tomar iniciativa e lutar para uma ruandesa assumisse a OIF, o que é milagroso. Eu tenho orgulho disso. Houve um momento em que eu era um bicho estranho, eu era a única que falava francês e não falava inglês. Insistia porque sabia bem tudo o que tinha feito para aprender essa língua, era mesmo uma oportunidade excepcional. É como vocês e o português.... nós falávamos kinyarwanda, não precisávamos falar inglês nem francês. Mas hoje todas as mulheres na política, em especial as mulheres embaixadoras, falam um francês impecável.

LL: Nos estudos literários, existem diferentes nomenclaturas utilizadas para definir os escritores, como francófonos ou de expressão francesa. Como você se define?

SM: O que isso quer dizer? Acho que vou tirar zero nesta questão! [risos]. Francófona, primeiramente. Eu acho que sou francófona e me expresso logicamente em francês, que se tornou minha segunda língua. Nasci ruandesa, é natural que minha primeira língua seja o kinyarwanda, uma língua materna ruandesa, que está presente nos meus escritos, mesmo que isso não se mostre no papel, o que explica as palavras que permanecem em kinyarwanda no meu texto.

LL: Como pesquisadoras em ensino de literatura e de língua estrangeira observamos a importância do contato com obras literárias de escritores e escritoras de diferentes países para os quais a literatura e a língua partem de outras perspectivas. Que autores contemporâneos trazem esses diferentes olhares?

SM: Ah! Vários! O que eu diria? Fico chateada de citar uns e não outros. Não é porque eu não os prefira, é porque eu não tenho tempo suficiente para ler todos. Hoje, é verdade que me interesso muito pelos escritos de Conceição Evaristo, porque eu tive a sorte excepcional de encontrá-la em Paraty. Fico feliz e agradeço a mim mesma por ter sido eu a dar o primeiro passo, sem conhecê-la. Sua personalidade me impressionou. Estávamos em um hotel, no café da manhã, e eu me sentei à mesa.

Eu gosto de olhar ao redor, então percorri o salão com o olhar e vi uma mulher! Por ir frequentemente aos Estados Unidos, posso às vezes identificar se é um homem americano ou africano, mas uma mulher é sempre o reflexo de uma africana! É isso! Vi uma mulher africana magnífica, uma rainha africana e fui atraída por ela, que parecia de uma potência só! Gosto, admiro muito as mulheres fortes que realmente exalam essa força. Foi então 
que eu fui, eu me joguei. Por mais que eu seja educada, quando eu admiro alguém, eu me atiro em cima dessa pessoa, o que provoca, algumas vezes, um constrangimento diante dos meus compatriotas franceses. É isso que eu gosto no Brasil. Eu me jogo mesmo! Temos o mesmo feeling, temos o mesmo calor humano. Na França, quando estou autografando, fico sentada, e assim continuo. O leitor está ali, devolvo seu livro, dou um sorrisinho e pronto. Mas, este calor humano de vir me abraçar é realmente específico do Brasil. É maravilhoso. Aliás, é perigoso para mim, porque eu me habituei a vir ao Brasil, com prazer, e quando volto para a França, continuo nesse clima: me jogo nos meus colegas,“Oh! Meu Deus! Não é possível!” [risos]

Então, Conceição, eu a descobri e tenho a sorte de suas obras serem traduzidas em francês. Assim, pude ler os livros dela, da Conceiça... aliás em kinyarwanda, de onde venho, o nome é Conceiça. Eu leio Conceiça e eu a chamo assim. A descobri pela editora que a publica em francês, Anacaona. Hoje, minhas leituras acontecem dessa forma. Sou estranha, leio os autores que encontro porque tenho uma memória visual. Tive a sorte de participar de uma mesa redonda com Ta-Nehisi Coates ${ }^{8}$, em Nova York. Comecei a ler suas obras e encontrei um menino maravilhoso, um verdadeiro afro-americano, muito íntegro, muito intelectual e ao mesmo tempo de um grande calor humano. Foi natural lê-lo e também Toni Morrison. Não posso citar outros porque alguém pode dizer “por que ela não me citou?”. Eu não dou os nomes. [risos]. Aqui está justificado: ler Toni Morrison é normal, é uma homenagem a tudo o que ela fez. Foi uma grande escritora universal, Nobel da literatura. TaNehisi Coates, ainda vou reencontrá-lo. Talvez ele faça o prefácio do meu próximo livro. Embora o tenha escolhido, a editora é quem vai decidir. Também ler Conceição Evaristo é natural, é um grande prazer. Encontro semelhanças com o que eu escrevo.

LL: Você pensa que o conceito de "escrevivência" (écrit-vivance), nas obras de Conceição Evaristo, seria uma forma de resistência?

SM: Escrevivência! Existe uma vivência, tem a palavra viver dentro, o que corresponde à própria pessoa de Evaristo. Escrevemos sobre histórias difíceis, um pouco dolorosas. Ela, sobretudo da escravidão e da posição do negro, o lugar que não lhe é dado, é um combate, uma resistência! Ontem, quando me perguntaram sobre a mulher na dor, havia as palavras "dor" e "mulher". Eu disse que a mulher sofre, mas este sofrimento, ela o transforma em força. É isso! Escrevivência é justamente para não chorar, mas sobretudo emitir uma força. Porque se chorarmos... desculpem-me, me recuso e me revolto. Quero absolutamente ser reconhecida, respeitada como todos. Um dos lados da migração está aqui, infelizmente... Escrevivência é resistir e viver, é isso! Portanto, não podemos continuar assim. É preciso que em um dado momento nos despertemos. Sei que não tenho a varinha mágica, que isso não se dá imediatamente, mas é meu modo de ver, de me engajar, de ter voz. Isso ainda vai demorar, mas se ninguém fizer nada, não chegará nunca. É a projeção de um futuro em um outro futuro.

LL: Você disse que escreve em kinyarwanda e depois traduz o texto para o francês, preservando as palavras que seriam intraduzíveis, palavras que são "gotas de leite materno de sua língua". Como é o processo de ser escritora e tradutora de sua própria obra?

SM: Não tenho um processo particular. Vamos falar do que já foi traduzido aqui, são livros de memórias. Escrevo em dois tempos. Houve o primeiro tempo, que era mais espontâneo, em que escrevia para mim, para o

\footnotetext{
${ }^{8}$ No Brasil, Entre o mundo e eu (2015), de Ta-Nehisi Coates, foi publicado pela Companhia das Letras - selo Objetiva.
} 
meu filho. Tinha pressa de salvar a memória porque estava ameaçada por mim mesma. Não sabia o que poderia acontecer de uma hora para outra. Não! Eu nunca me descontrolei ao ponto de me tornar completamente louca, de cair na loucura e de não ser mais capaz de reencontrar minhas lembranças, porque eu escrevia sobre o que foi vivido. Minha mãe salvava os filhos e eu, eu salvei a memória. Portanto, não havia um processo, joguei as palavras como elas me chegavam.

\section{LL: Em kinyarwanda?}

SM: Sim! Em todos os momentos do dia e da noite, era hora de "salvar a memória". Foi assim sobretudo com Baratas e $A$ mulher dos pés descalços. Esses dois, eu lembro de ter despejado em um caderno que ficou todo escrito depois de ter colocado tudo o que importava. Mesmo na rua, indo trabalhar, eu tinha que parar, nem sei como não sofri um acidente! Como sou assistente social, percorro os campos da Normandia em meu carro. Quando as ideias apareciam, eu tinha realmente que parar no meio de uma rua, porque um monte de coisas me vinha desordenadamente. Eu tinha um gravador que colocava na frente do painel... tinha até esquecido dele porque agora não preciso mais. Escrevo normalmente refletindo, não tenho mais essa angústia diante da folha em branco. Não, não é um trauma. Depois vinha o segundo momento de escrita, o de publicar. O processo era juntar minhas palavras jogadas soltas aqui e ali para fazer um texto coerente e sem modelo, eu nunca tinha escrito antes! Nem mesmo sabia como escrever! Até então, eu só tinha lido. Na leitura, há pessoas que são muito hábeis, que retêm como a construção do texto é feita. Eles vão fundo na leitura porque pensam em um dia escrever. Geralmente, isso não funciona comigo.

Refiro-me aos contos da minha mãe porque ela era, a seu modo, uma intelectual oral completa. Ela não escrevia, mas tinha um fio condutor nas suas histórias. Portanto, coloquei-me à disposição e dediquei-me a contar bem, porque era um patrimônio, uma história que ela nos transmitia, que deveria ser bem contada para que a gente pudesse digerir. Como era o papel a ser desempenhado por todas as mulheres, por todas as meninas, minha mãe pensava e dizia consigo mesma: "minhas filhas serão contadoras de histórias". Meu modelo foi minha mãe. Por isso, escrevendo, eu fazia como a contadora de histórias, sem pensar em seduzir o editor, pensava em contar bem.

A autora segue comentando sobre o processo de sua escrita e do episódio de deportação em sua infância.

SM: Em Baratas, me esforcei para ficar na postura da menininha de três anos que se vê desembarcada em Nyamata, jogada. Nos desembarcaram como pedras, como nas caçambas para construção, vocês imaginam? Pegam caçambas para construção, pedras, e depois na obra descarregam... conseguem vislumbrar isso que eu digo?

$\mathrm{Na}$ deportação, em Nyamata, foi semelhante, eu guardo essas imagens. Nos enfiaram nos caminhões, como pedras, realmente espremidas, e uma vez que chegamos no destino, nos descarregaram no pátio empoeirado de Nyamata... São imagens que ficaram. E eu, que tinha 3 anos, me sentei na poeira: a gente não se reconhecia, a gente não se encontrava e a poeira subia. “Onde está mamãe? Onde está papai? Onde estão os irmãos e irmãs?”. Fiquei sentada na poeira com as pernas cruzadas. Uma criança sob a poeira. Quando escrevi Baratas, de fato, tomei essa postura. Fiquei sentada nesse pátio, saí de lá e segui todo o curso da minha vida em Nyamata na 
postura dessa menininha, da inocência que não quer enganar, que vai ser objetiva, pois quer descrever o mundo que a rodeia. O mundo é tão ruim quanto alegre. É por isso que há festas nos vilarejos, eventos. Era absolutamente necessário que o leitor pudesse sentir por trás do texto uma menininha que conta uma história que é a sua vida, dolorosa, mas ao mesmo tempo engraçada. Eu disse a mim mesma: "e se eu contasse uma história como em um caderno de viagem?”.

Quando me ouviam em conferências na França, sobre Baratas, me diziam: "eu não ousei ler esse livro porque tive medo de que fosse duro demais" e eu respondia: "Não, não! vocês vão ver, vão rir" e depois até me perguntavam, "Por que há humor na sua escrita?".

Fui criada sob uma proteção máxima da minha mãe que não queria que fossemos tristes, mas sim que fossemos crianças felizes, e isso nos salvou, então o coloquei em minha escrita. O humor tem a capacidade de atravessar as coisas e tratava-se de algum jeito de relativizar a situação. Era necessário agarrar-se ao humor, por ser uma tradição, mas nessas condições difíceis era absolutamente preciso. Os pais tentavam criar um pouco de humor, um pouco de felicidade, de alegria... Como no filme $A$ vida é bela.

Era assim em Nyamata! Eu não queria transmitir sofrimento ao leitor, tinha uma história para contar, mas não queria que eles ficassem infelizes, e sim que encontrassem uma força no que escrevi. Gostaria que vissem que é uma história dramática, mas ao mesmo tempo, que tem uma força desta vida, tem resistência. Por isso eu penso que é o livro da minha mãe. Escrevi com muito carinho, triste por vezes, mas com muito mais afeto do que tristeza. É normal porque eu a amava muito, é a minha mãe. Como a gente era ameaçada a todo momento de morrer, ela não dormia, vivia apenas para salvar os seus filhos. Eu era a mais velha das minhas irmãs, a única a ajudar meus pais no vilarejo. Eu nem podia me imaginar sem minha mãe. Era algo que me fazia chorar, só de pensar que ela pudesse morrer. Até o momento em que ela e meu pai vieram me dizer que eu deveria partir e permanecer viva por eles, porque tive a sorte de aprender o francês, que era o passaporte para a vida e para navegar o mundo inteiro. Os outros que não aprenderam francês, para onde iriam? Vocês se dão conta? Eu tinha 16 anos, foi uma renúncia, mas eu não tive escolha. Desse modo, quando me perguntam "Como você fez para escrever?”. Eu não podia não responder a essa missão que era o meu dever. Não podia ser uma filha ingrata. Se eu não tivesse escrito, eu teria sido a pessoa mais infeliz do mundo, não teria sobrevivido.

Mãezinha, eu não estava lá para cobrir o seu corpo, e tenho apenas palavras - palavras de uma língua que você não entendia - para realizar aquilo que você me pediu. E estou sozinha com minhas pobres palavras e com minhas frases, na página do caderno, tecendo e retecendo a mortalha do seu corpo ausente. ${ }^{9}$

A autora passa então a falar sobre um dos seus livros, até então não publicado no Brasil, Un si beau diplôme! (Gallimard, 2018), escrito em homenagem a seu pai.

SM: Foi por causa do meu pai que fui à escola. Se vocês lerem esse novo livro, vão entender. Em Baratas, conto que no dia do Exame Nacional, tinha me recusado a prestá-lo porque isso não servia pra nada. Eu não era má aluna, tinha uma capacidade normal de fazer um exame e ser aprovada. Não eram as capacidades mentais que me faltavam, mas eu não iria me humilhar em fazê-lo com quota dos $10 \%$ reservada aos raros tutsis que haviam

\footnotetext{
${ }^{9}$ Mukasonga, S. A mulher de pés descalços. Trad. Marília Garcia. São Paulo: Editora Nós, 2017, p.7.
} 
permanecido no interior de Ruanda. Em Nyamata não tinha quota, ser aprovada seria um milagre, eu não estava nos 10\%. Minha passagem para o Lycée Notre-Dame de Citeaux (conhecido como Notre-Dame du Nil) foi anunciada pela rádio, porque era assim que os aprovados eram anunciados, algo que era reservado aos abastados, aos ricos. Só uma pessoa tinha rádio em Nyamata e tinha escutado que Mukasonga tinha sido admitida. E isso foi a festa de todo o vilarejo. Todo mundo trouxe feijão, batata-doce, banana. Que festão! Todo mundo! Todas as avós! Todas as anciãs desfaziam o nó de seus panos para me dar um pouco de dinheiro, para contribuir com a minha ida ao Lycée Notre Dame de Citeaux. Porque eu seria a embaixatriz delas.

Era o dia do exame que eu tinha recusado fazer. Eu gostava muito de ir para roça com a minha mãe, me preparava para ser uma boa camponesa também. Então, peguei meu pequeno arado, coloquei sobre os ombros, e meu pai disse: “O que é isso?". Meu pai era um grande intelectual, ele tinha frequentando cinco anos de escola primária. Isso era tudo o que havia em sua época. Era o período colonial, e nos cinco anos da escola primária aprendia-se o swahili, a língua de comunicação com o colonizador, utilizada entre os colonos e a população, a massa camponesa. Meu pai sabia ler e escrever, ele lia a Bíblia, para ele era o livro mais importante! Sua Bíblia, seus óculos que o padre lhe havia dado [risos] e sua caneta azul, sempre presa no bolso. Isso está em Un si beau diplôme!, meu próximo livro a ser lançado no Brasil.

E então, ele disse "não!", colocou suas roupas de domingo, de tecidos brancos, pegou seu bastão paterno que usava para nos castigar se não obedecêssemos, mas que ficava sobre seus ombros, se fossemos obediente. [risos]

Ele me disse: “coloque seu vestido azul, vamos fazer o Exame Nacional”. Não era só eu que prestava o exame, era também ele. "Vamos fazer essa prova" e então a gente partiu, de pés descalços. A escola ficava a $10 \mathrm{~km}$, que fizemos a pé, bem rápido, e eu passei no Exame Nacional e fui para o Lycée Notre Dame de Citeaux. Tudo isso para lhes dizer que quando eu fiz uma conferência em São Paulo, no público, alguém se levantou e disse: "mas, você escreve sempre sobre sua mãe, sobre as mulheres... você nunca fala sobre o seu pai. Você não teve pai“" Meu Deus! Eu fiquei... Eu que nunca quis ser uma filha ingrata. Eu disse: “mas, eu fui horrível!” Foi graças a ele que eu fui aprender francês. Se eu não tivesse aprendido francês, eu teria ficado em Nyamata! E o facão... Eu, como todo mundo, não teria escapado do facão. Por causa disso, eu quis escrever sobre o meu pai e o livro se chama Un si beau diplôme !, porque era essa a obsessão dele (o diploma). Ele estava convicto e tinha jurado que se um dos seus filhos escapasse, seria por meio da escola. Ele sabia o que era isso, pois foi salvo pela escola. Foi um órfão de pai e mãe, não tinha nada, e ganhou algum status porque tinha feito seus cinco anos de escola primária e tinha se tornado secretário local. Ele fazia de tudo e falava bem swahili, que nessa época era como falar inglês, português, francês, chinês.

Era um homem importante. E foi assim que que nós nos tornamos os indesejáveis. Quando chegamos em Nyamata, foram por muitas vezes fazer procurar onde estávamos... Nós nos enganamos pensando que talvez tivessem deportado os hutus, ou então os tutsis que não eram maus, que eram gentis... O fato é que um pesadelo começava na cidade. Não víamos mais meu pai, ele era visto apenas como o verdadeiro colonizador. Era ele o malvado, o colonizador, aquele que oprimiu os camponeses. Tanto que em 2014, quando fui ao vilarejo de Magie, encontrei uma velhinha que morava na casa onde vivemos, e que ainda se lembrava disso. Nós fomos deportados em 1960 e as pessoas ainda se lembravam do pesadelo no vilarejo. Então, Un si beau diplôme! é o livro do meu pai e essa questão foi salutar para mim, porque é verdade, a gente escreve facilmente sobre a mãe. 
LL: Nós, brasileiros, temos muito nossas raízes indígenas e africanas cortadas por um racismo velado, mais difícil de identificar, de denunciar e de combater. Da mesma maneira, nós não nos vemos todos(as) como negros(as). Quem somos nós agora? Como sugere o título do livro de Bianca Santana, Quando eu me descobri negra, a identidade não é algo evidente. Para nós, refazer essa conexão com nossas raízes é uma forma de se aproximar da humanidade face ao horror imposto por aqueles que estão no poder, sobretudo neste momento. Ao procurarmos nossas raízes, o que podemos oferecer nessa troca à África? Não é algo que começou agora, mas é urgente. Como você vê isso?

SM: Normalmente é uma riqueza. É uma grande riqueza. É o país onde todo mundo deveria viver em harmonia. Apesar da dimensão do genocídio em Ruanda, o que nós sabemos bem é que negaram nossa identidade ruandesa. Nós, tutsis, não queríamos que fossemos negados como ruandeses e exilados no exterior!

Nós, ruandeses, não éramos numerosos e, no entanto, podiam nos encontrar no mundo inteiro. E outra coisa, não tínhamos direito a ter os documentos, a carteira de identidade. Me lembro que a maior parte dos intelectuais foi exilada, sobretudo no Senegal, país que gosto muito. Respeito muito os senegaleses, porque eles acolheram e protegeram nossos intelectuais que eram sobretudo médicos. Os grandes médicos estavam no Senegal, porque não podíamos passar pelo Burundi. Aqueles que queriam estudar medicina só podiam fazer dois anos de estudo no Burundi e depois prestar um concurso para ir estudar medicina na Europa, na Bélgica, na França, mas os ruandeses não podiam ir para Europa. O Senegal se tornou a Europa para nós, porque era o único país que não exigia passaporte. Não tínhamos nada, éramos apátridas. Nós tínhamos realmente o documento de apátridas. Não tínhamos identidade, e recusávamos a não ter.

Eu estava no Djibouti, foi no início de 1990 e essa situação fez movimentar todos os exilados que estavam no Uganda a se organizarem e dizerem: "Não! Pare! É preciso rasgar a camisa. É preciso se mexer! Não virá assim fácil, de mão beijada. É preciso defender nossa posição". Não éramos muitos, mas o que conta não é o número, é a força, a energia. Era isso que nós queríamos ter. No final das contas, não somos uma vida? Não podemos viver eternamente sem ter uma identidade, isso é tudo, saber quem somos é super importante! Não podemos nos construir, sermos bem-sucedidos, termos força, nos impor na humanidade, se nós não soubermos primeiro quais são nossas raízes, isso é profundo! Era absolutamente necessário reencontrar nossa identidade ruandesa. Atenção, desconfiem, tomem a língua como algo de muito importante: fomos salvos pelo kinyarwanda porque foi minha identidade inegável. Ninguém podia me privar da minha língua. É por isso que nos meus livros tem palavras em kinyarwanda, mesmo que eu escreva em francês. Lembro que fiquei chocada um dia, em Djibouti, durante uma festa na casa de um casal, uma moça egípcia e seu marido italiano. Em um dado momento, a moça diz "eu me sinto italiana". Eu dei uma gargalhada e disse: "Antes de ser italiana você é africana" e, defendi minha posição. Foi uma coisa que se impôs naturalmente, eu não tinha imaginado até que ponto eu estava em harmonia com as minhas origens. Eu disse: "Não!" Por mais que eu fale francês, que eu tenha um documento de identificação francês. Aliás, o primeiro documento que tive: "eu francesa?”. Sou profundamente africana, falo kinyarwanda e tenho a sorte de ter o nome Mukasonga, tipicamente ruandês.

Por tudo isso, não podiam negar minha identidade ruandesa. Penso que foi o que salvou os sobreviventes como eu. O genocídio aconteceu, é triste, mas depois não ficamos desesperados para reconstruir nosso país e dar outro futuro aos nossos filhos, uma outra imagem. Por mais que dissessem que não éramos ruandeses, que 
vínhamos de outro lugar, nós sempre estávamos à vontade, profundamente integrados, certos de que temos raízes, de que somos ruandeses.

Então, é por isso que digo que o genocídio deve ser ensinado às nossas crianças e isso será o primeiro reflexo, é necessário que as crianças fiquem à vontade com a história delas, é importante não falsificar.

É importante que ninguém venha lhes dizer: "em Ruanda, os tutsi, os hutus... Isso nunca existiu”. Sim, existiu! Infelizmente, nós criamos isso. É um erro que devemos corrigir, e agora nós somos ruandeses. As crianças não devem ter vergonha disso. É lamentável, mas é nossa história. Ela foi muito dolorosa, mas é nossa, devemos reconstruir nossa Ruanda. Não devemos esconder.

Hoje o que eu lamento no Brasil, pelo que escuto de vocês, é que não há muito sendo feito pela história da escravidão. Não tem nenhuma vergonha, isso existiu. Não queremos viver nisso, mas está feito e é lamentável. É preciso aceitar, ensinar nas escolas, falar da realidade, sem historinhas de mentira, sem dizer que alguém é melhor ou pior por ter a pele mais clara ou por ser mestiço. Não! Aceitem sua identidade! É isso que eu gosto na obra de Ta-Nehisi Coates, que diz que não é a cor que conta. O ser humano não é feito de cor, de sua exterioridade, desse envelope, ele é feito do que aconteceu. Penso que o que é importante para nós, é vivermos juntos a cada dia, é trabalhar juntos pela dignidade do nosso país.

É isso que conta, o que nós vivemos, o que nós comemos e falamos juntos. Tudo isso. Ainda mais vocês que tem a sorte de falar a mesma língua. É isso que eu posso dizer. É preciso procurar nossas raízes. Se não temos raízes claramente definidas, são mentiras, falsificações, invenções. Isso não vai dar certo. Não devemos medir palavras com as crianças nas escolas primárias, devemos usar palavras justas para explicar o que aconteceu, de onde veio porque desejamos que vivam diferente, em harmonia, que vivam todos juntos na mesma luta de dizer que devemos ser dignos de nosso país.

LL: Você disse numa entrevista que você escreve em um francês acessível para todos. Isso seria um ato político de inclusão do(a) leitor(a)?

SM: Por que isso seria um ato político? De transmissão simplesmente?

LL: Mesmo para nós, que aprendemos o francês, existem livros que não nos parecem acessíveis, com os quais não nos identificamos, então nos afastamos. Mas outros, quando lemos, nos apegamos, como o caso de Petit Pays (2016) de Gael Faye e de Frère d'Âme (2018) de David Diop. Outros clássicos da literatura em francês não necessariamente nos prendem.

SM: Sim, certamente. Quando escrevo, penso em transmitir, em compartilhar essa história que não é apenas minha, é a história do genocídio. Eu queria atingir o maior número de leitores, é normal. Não pensei no sucesso. Mas pode ser que, por escrever por meio de uma expressão acessível da língua, o sucesso tenha vindo, para mim e para o Gael. De alguma forma, acredito que quando escrevemos, vemos filigranas no texto, nossa personalidade... Quem eu sou? Eu sou uma ruandesa de origem modesta. Não devo complicar as coisas. Sou muito íntegra em ter uma família modesta, onde cresci, meus valores. Em respeito ao outro, por que complicar as coisas? Por que escrever de uma maneira em que nem eu me sentiria à altura, complicada, se existe uma maneira mais simples de se expressar? Para incluir todo mundo, para que todo mundo possa simplesmente me ler. Foi importante, eu precisava que o maior número de pessoas tivesse acesso à minha história e, ao mesmo tempo, isso faz parte dos valores profundos que adquiri da minha família. Aliás, sou assistente social e no 
cotidiano tenho que me fazer entender pela população mais simples, a mais carente. Devo estar presente sendo eu mesma. Não posso fazer uma coisa que seja complicada, por esses valores profundos, pela minha história, que devo compartilhar e pela profissão que escolhi. É isso, é simplesmente isso.

LL: Muito obrigada!

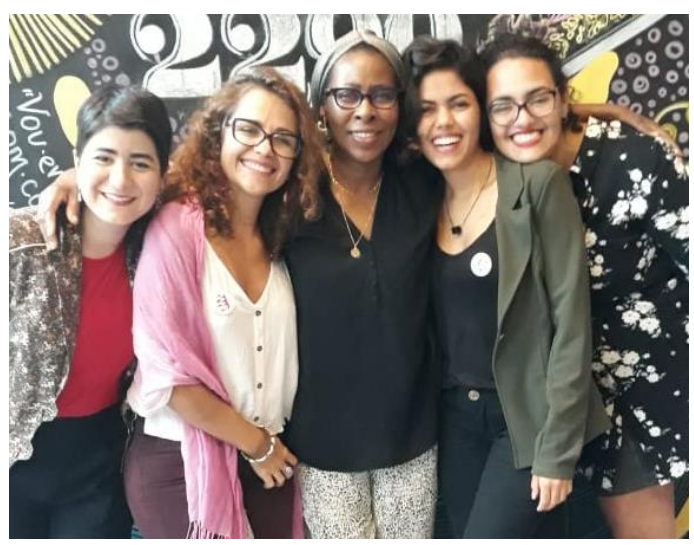

Mariana Firmino, Sandra Coeli, Scholastique Mukasonga, Larissa Esperança e Lucília Teixeira
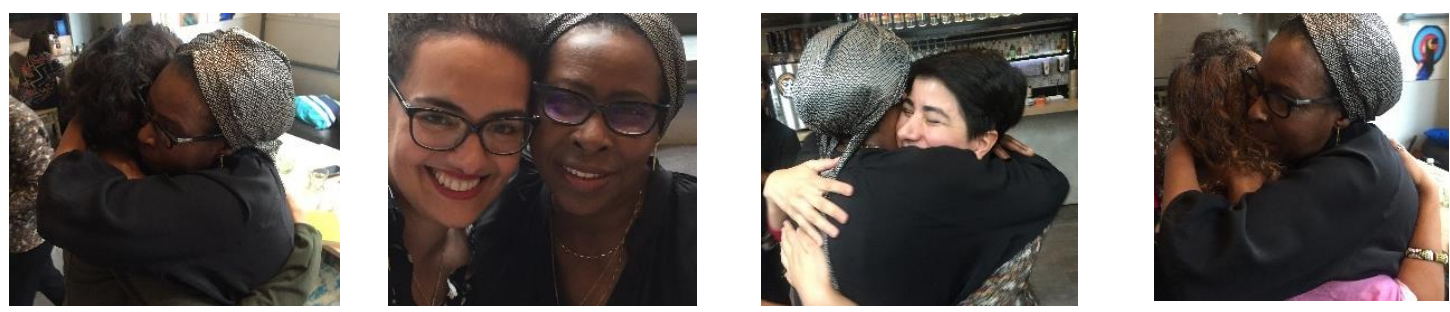

grandes abraços

Depois de sua participação no prêmio National Book Awards em Nova York, a autora seguiu para Ruanda para participar da festa de estreia do filme Notre Dame du Nil ${ }^{10}$ (2019), dirigido pelo cineasta e escritor francoafegão Atiq Rahimi. Segundo ela, enquanto não fosse apresentado em Ruanda, o filme não poderia ser difundido em nenhum outro país. Antes de sua estreia em Ruanda, o longa-metragem foi exibido em Toronto, estando entre os cinco filmes que abriram o Festival du film de Toronto.

\section{Liuros da autora publicados no Brasil:}

MukAsongA, Scholastique. A mulher de pés descalços. Trad. Marília Garcia. São Paulo: Editora Nós, 2017.

Baratas. Trad. Elisa Nazarian. São Paulo: Editora Nós, 2018a.

Nossa Senhora do Nilo. Trad. Marília Garcia. São Paulo: Editora Nós, 2018b.

\section{Referências bibliográficas}

CoAtes, Ta-Nehisi. Entre o mundo e eu. Trad. Paulo Geiger. São Paulo: Companhia das Letras - Objetiva, 2015.

DiOP, David. Frère d'âme. Paris : Seuil, 2018.

FAYE, Gael. Petit Pays. Paris : Livre de Poche, 2017.

\footnotetext{
${ }^{10}$ Sobre o filme Notre-dame du Nil (2019), consultar: <https://www.imdb.com/title/tt8690948/>. Acesso em: 28 ago 2020.
} 
MUKASONGA, Scholastique. Un si beau diplôme! Paris : Gallimard, 2018.

La Femme aux pieds nus. Paris : Gallimard/Continents Noirs, 2008.

The Barefoot Woman. Nova York: Archipelago Editions, 2018.

Notre Dame du Nil. Paris : Gallimard, 2014.

. Inyenzi ou les Cafards. Paris: Gallimard/Continents Noirs, 2006. 